\title{
Use of an electronic cognitive aid by a person with Korsakoff syndrome
}

Citation for published version (APA):

de Joode, E. A., van Boxtel, M. P. J., Hartjes, P., Verhey, F. R. J., \& van Heugten, C. M. (2013). Use of an electronic cognitive aid by a person with Korsakoff syndrome. Scandinavian Journal of Occupational Therapy, 20(6), 446-453. https://doi.org/10.3109/11038128.2013.821161

Document status and date:

Published: 01/01/2013

DOI:

10.3109/11038128.2013.821161

Document Version:

Publisher's PDF, also known as Version of record

Document license:

Taverne

Please check the document version of this publication:

- A submitted manuscript is the version of the article upon submission and before peer-review. There can be important differences between the submitted version and the official published version of record.

People interested in the research are advised to contact the author for the final version of the publication, or visit the DOI to the publisher's website.

- The final author version and the galley proof are versions of the publication after peer review.

- The final published version features the final layout of the paper including the volume, issue and page numbers.

Link to publication

\footnotetext{
General rights rights.

- You may freely distribute the URL identifying the publication in the public portal. please follow below link for the End User Agreement:

www.umlib.nl/taverne-license

Take down policy

If you believe that this document breaches copyright please contact us at:

repository@maastrichtuniversity.nl

providing details and we will investigate your claim.
}

Copyright and moral rights for the publications made accessible in the public portal are retained by the authors and/or other copyright owners and it is a condition of accessing publications that users recognise and abide by the legal requirements associated with these

- Users may download and print one copy of any publication from the public portal for the purpose of private study or research.

- You may not further distribute the material or use it for any profit-making activity or commercial gain

If the publication is distributed under the terms of Article $25 \mathrm{fa}$ of the Dutch Copyright Act, indicated by the "Taverne" license above, 


\title{
Scandinavian Journal of Occupational Therapy
}

\section{Use of an electronic cognitive aid by a person with Korsakoff syndrome}

\author{
E.A. de Joode, M.P.J. van Boxtel, P. Hartjes, F.R.J. Verhey \& C.M. van Heugten
}

To cite this article: E.A. de Joode, M.P.J. van Boxtel, P. Hartjes, F.R.J. Verhey \& C.M. van Heugten (2013) Use of an electronic cognitive aid by a person with Korsakoff syndrome, Scandinavian Journal of Occupational Therapy, 20:6, 446-453, DOI: 10.3109/11038128.2013.821161

To link to this article: https://doi.org/10.3109/11038128.2013.821161

曲 Published online: 24 Jul 2013.

Submit your article to this journal ¿

Џll Article views: 282

Q View related articles $₫$

Citing articles: 3 View citing articles $\llbracket$ 


\title{
ORIGINAL ARTICLE
}

\section{Use of an electronic cognitive aid by a person with Korsakoff syndrome}

\author{
E.A. DE JOODE ${ }^{1}$, M.P.J. VAN BOXTEL ${ }^{1}$, P. HARTJES ${ }^{2}$, F.R.J. VERHEY ${ }^{1}$ \& \\ C.M. VAN HEUGTEN ${ }^{1}$ \\ ${ }^{1}$ School for Mental Health and Neuroscience, Maastricht University, Maastricht, The Netherlands, and ${ }^{2}$ Pro Persona, \\ Winkler Kliniek, Clinic for Neuropsychiatry and Behavioural Neurology, Wolfheze, The Netherlands
}

\begin{abstract}
Objective: The purpose of the current study was to evaluate the feasibility and the effectiveness of the use of a customized personal digital assistant (PDA) to support cognitive functioning in a person with Korsakoff syndrome. Method: The PDA was compared with no external support and the use of a memory watch in a single case experimental design. Three main personal goal tasks were defined: "arrive at appointments on time", "execute a long-term task successfully", and "remember to ask for medication". Results: No significant differences were found between the use of the memory watch and the use of the customized PDA. PDA use was perceived as feasible and effective and was considered as a more comprehensive aid than the memory watch. Conclusion: This study shows that a person with Korsakoff syndrome is able to use and benefit from a customized PDA. Replication of these findings in a larger effectiveness study is necessary.
\end{abstract}

Key words: treatment outcome, Korsakoff syndrome, handheld computers

\section{Introduction}

The use of digital aids such as smartphones, personal digital assistants (PDAs), and cell phones has become quite common in our daily lives. Such devices help us to keep track of our appointments and to-do-lists, to organize our day or week, and these devices have the ability to manage and store information. People with deficits in memory, planning, or attention function as a result of brain injury can also benefit from this sort of cognitive support (1-5). Digital aids are especially useful to support prospective memory; the use of PDAs can successfully influence the timely execution of tasks such as taking medication or feeding pets, and can also help remember important dates such as anniversaries (5). Furthermore, retrospective memory could also be supported; e.g. recording important conversations with a health care professional or keeping a daily journal on the PDA or smartphone. In this way, people can keep a record of past events too.
It has been shown that the effectiveness of the use of a customized PDA by people with acquired brain injury, such as stroke or traumatic brain injury, is (at least) equal to and a valuable alternative to paperand-pencil aids (6). It is therefore important to identify which other patient groups with similar cognitive deficits could effectively use such devices to enhance independent functioning. For example, people with Korsakoff syndrome who suffer from severe memory deficits may benefit strongly from an electronic cognitive aid to remind them of appointments and tasks.

At present about 8000 people in the Netherlands have been diagnosed with Korsakoff syndrome and this number is still increasing (7). Alcohol abuse and subsequent malnutrition can lead to a thiamine deficiency, which causes brain damage associated with this syndrome (8). Patients suffer from severe memory disorders and have limited capacities to learn new information. Furthermore, they may be prone to confabulate due to intrusion errors or distortions in

Correspondence: C.M. van Heugten, PhD, Department of Psychiatry and Neuropsychology, School for Mental Health and Neuroscience, Maastricht University, PO Box 616, 6200 MD Maastricht, The Netherlands. E-mail: c.vanheugten@maastrichtuniversity.nl 
the retrieval of information from memory (8). Executive dysfunction can cause a lack of initiative and apathy (9).

People with Korsakoff syndrome encounter memory difficulties on a daily basis, for instance when making and keeping appointments, remembering tasks, such as posting a letter, as well as recognizing people or remembering the layout of a health care facility. They need constant reminding by others and need aids to compensate for these problems. Furthermore, they do not always use aids, and must often be prompted by family members or professionals to do so (7).

Rehabilitation training for this patient group tends to focus on three strategies: adaptation of the environment, using the limited memory capacity in the most effective way, and deployment of external aids to compensate for the cognitive deficits (10).

Although the learning capacity of people with Korsakoff syndrome is limited, implicit memory remains reasonably intact (10). This includes the response to priming or cues as well as procedural (perceptuo-motor) memory. Successful training in the use of external aids is based on repetitive training, using an errorless learning approach (11) and by taking small steps. During this process, instructions should be brief and training should focus on learning specific skills instead of a general strategy (9). Hypothetically, these specific characteristics of people with Korsakoff syndrome would enable them to learn to use a digital aid. Still, the question remains whether they actually are able to master the use of an electronic external aid.

A single case study by Wilson et al. (11) has shown that a 35-year-old person with Korsakoff syndrome was able to learn how to use an electronic memory aid with an errorless learning strategy. However, this study involved only a very simple task: entering a phone number. In another study (12) a 63-year-old person with Korsakoff syndrome was able to use a simple electronic diary, but this participant did not enter appointments himself. The authors compared the use of this electronic diary with a system of verbal cueing by the nursing staff. They concluded that due to the introduction of the electronic diary after the successful use of verbal cueing, the use of an electronic aid did not show an additional improvement in the attendance at therapy groups by the participant. To our knowledge this study by Morgan and colleagues is the only comparative study published so far in people with Korsakoff syndrome. Other authors also have advised the use of electronic cognitive aids for people with Korsakoff syndrome, especially because of their increased need for external cueing $(13,14)$.

Thus, in studies conducted over 15 years ago, people with Korsakoff syndrome were able to use and benefit from simple electronic aids. Modern electronic aids have a much wider range of applications and possibilities, especially PDAs and smartphones, and may provide more support than previous simple prompting devices. However, modern cognitive aids may also require more intensive training and place more cognitive demands on the user, casting doubt on the feasibility of its use in this patient group.

The purpose of the current study was twofold: first, to evaluate the feasibility of the use of a customized PDA to support cognitive functioning in a person with Korsakoff syndrome, and second, to compare the effectiveness of this PDA on the achievement of predefined goal tasks with baseline assessments when no memory aid was used, and when using a memory watch. A single case experimental design (SCED) (15) was used to explore these questions.

\section{Materials and methods}

\section{Case history}

The participant was a 40-year-old man with diagnosed Korsakoff syndrome, who was a resident at a neuropsychiatry and behavioural neurology unit at a mental health care facility in the Netherlands. As he showed interest in using a different aid than a paper diary or a memory watch, which were the usual aids at this facility, his therapist suggested the use of a customized PDA. As this facility was enrolled in another study, i.e. a randomized controlled trial into the efficacy of this PDA in people with acquired brain damage, the knowledge and equipment was already available. The participant provided written informed consent to participate in this single-case spin-off study and for the publication of the results. Medical ethics approval was obtained for investigating the efficacy of the PDA in people with acquired brain injury, including - but not limited to - stroke, traumatic brain injury, Korsakoff syndrome, and brain tumours.

Two months after admission a neuropsychological evaluation was performed. Five months later a second neuropsychological evaluation (five months prior to the start of this study) showed persisting deficits in verbal memory: the Visual Verbal Learning Test (VVLT) and the Rivermead Behavioural Memory test; the scores showed that encoding, delayed recall, and recognition were impaired (all scores below 1st decile). For instance, the learning curve of the VVLT was flat (2-4), and he could recall just one word after 20 minutes' delay. He showed a tendency to confabulate, had difficulties with orientation in time, and showed a lack of initiative. Furthermore, he scored low (6) on a depression symptom questionnaire (Beck Depression Inventory-II (16)), a score between zero 
and 13 reflecting minimal depressive symptoms and being within the normal range. Actual medication use was the antidepressant drug sertraline, $50 \mathrm{mg}$ twice a day, and thiamine (vitamin B1), $25 \mathrm{mg}$ four times a day.

The participant's educational level was at "intermediate vocational training", indicating education that prepares for a specific trade or craft, which includes both theoretical lessons and practical handson training. He had been working as a truck driver for the same company for eight years. Seven months prior to admission he had been fired from his job. His alcohol consumption increased and his nutrition intake was insufficient. He was admitted to a general hospital with symptoms of ataxia and ophthalmoplegia, which were later diagnosed as Wernicke's encephalopathy. He suffered from anosognosia: he perceived his alcohol use as not being problematic and his nutritional intake as being sufficient. Furthermore, the participant did not recognize having cognitive deficits at the time of admission.

\section{Study design}

This study is part of a larger study (6) and the first to investigate the use of an electronic aid by a person with Korsakoff syndrome. A single-case study design was chosen, as the flexibility and relatively short setup time of this type of study would enable a tailored intervention programme and sufficient experimental flexibility to evaluate clinical outcome (15).

A single case experimental design (SCED) (15) with a 24-week A-B-C-A design was used with both quantitative and qualitative observations. The multiple baseline and treatment phases in this methodology enhanced control of extraneous, potentially confounding factors. For example, we included an Aphase in which no cognitive aid was used instead of only comparing the memory watch (B-phase) with the use of the electronic device (C-phase). In this way baseline functioning could be determined. In addition, we tried to measure during the treatment phases and not only at the end of a treatment period. In the first two weeks of the study period (A), the participant refrained from using any memory aid (no aid). In weeks three and four he used the memory watch (Timex ${ }^{\mathrm{TM}}$ watch, see below) (B) and in weeks five to 22 (C) he used the PDA with Planning and Execution Assistant and Trainer software (PEAT) (see below). In the last two weeks again he did not use any memory aid (no aid) (A).

Treatment phase was considered as the independent variable, and the attainment of goals (see below) was the dependent variable.

The participant was trained by an occupational therapist in the use of the PDA using an errorless learning procedure with repetitive step-wise instructions. The therapist was experienced in training people with cognitive deficits to use external aids, such as diaries, mobile phones, and PDAs.

\section{Electronic cognitive aids}

Before the start of the trial, the participant used a Timex Ironman Data Link USB memory watch (17). This is a relatively simple electronic memory aid that may prompt auditory alarms and display text messages. With the accompanying computer software, users can program the watch and customize its features.

We screened commercially available devices for convenience and adaptability to participants' individual needs and wishes. The PDA we selected was a Hewlett-Packard iPAQ 114 (6). After reviewing and comparing several software options such as Handi (18) and ISAAC (19) we opted for the Planning and Execution Assistant and Trainer (PEAT) software (20) in our RCT and therefore also in this SCED. The PEAT software provides a reminder function and supports enhanced flexibility in the planning of appointments. A "floating task" function allows users to deal with deviations from normal routine: the software may schedule a task when there is enough time available and is pushed to another time slot if another event occurs. This feature is of importance to people with brain injury who usually have difficulties with planning, organizing, and rescheduling daily activities. Also, each function is customizable to fit the specific needs of the user. The software offered complete control to the occupational therapist to limit or expand the functionality of PEAT during the course of the training, based on the progress made by the participant.

There are four main modules in PEAT: the cue card, the diary, the notes section, and the names section. The cue card shows the current and the next task in order to give users a reminder of current and upcoming events. The diary shows the schedule in a day, week, or month view and users can add or change appointments or to-do tasks. The notes section allows the user to take written and voice notes and to link these directly to the relevant appointment or task in the diary. In the names section contact information can be stored, which can also be linked to tasks in the diary. The user is always auditorily and visually reminded at the start and end of a task.

The authors translated the software into Dutch, in close collaboration with the PEAT developers. PEAT software completely takes over the control of the PDA, thereby blocking access to the underlying Windows Mobile (version 6) operating system. This was 
Table I. Mean scores on the three goals in each trial phase.

\begin{tabular}{lcccc}
\hline & $\begin{array}{c}\text { Phase A: } \\
\text { No aid } \\
\text { Weeks 1-2 }\end{array}$ & $\begin{array}{c}\text { Phase B: } \\
\text { Memory watch } \\
\text { Weeks 3-4 }\end{array}$ & $\begin{array}{c}\text { Phase C: } \\
\text { PDA } \\
\text { Weeks 5-22 }\end{array}$ & $\begin{array}{c}\text { Phase A: } \\
\text { No aid } \\
\text { Weeks 23-24 }\end{array}$ \\
\hline Goal 1: being on time & $0.83(0.14)$ & $1.00(0.00)$ & $0.84(0.19)$ & $0.47(0.27)$ \\
Goal 2: long-term goal & $0.61(0.35)$ & $0.88(0.73)$ & $0.73(0.26)$ & $0.00(0.00)$ \\
Goal 3: remembering medication & $0.34(0.31)$ & $\star$ & $0.86(0.14)$ & $1.00(0.00)$ \\
\hline
\end{tabular}

Note: ${ }^{\star}$ No scores available.

done to lock the user interface and to avoid confusion for the user.

\section{Goal tasks}

The occupational therapist who trained the participant in using the memory aids defined three main goals relevant to the participant's daily life functioning at the start of the trial. The first goal was "to arrive at appointments on time", for instance at another therapy session or activity, such as carpentry. The person with whom the participant had this appointment scored the attainment of this goal. The second goal was "to execute a long-term task successfully"; this could either be to remember to bring the proper equipment for cognitive training, or to remember to send a specific email message at a later date. For example, the occupational therapist would ask the participant on Tuesday to send her an email message on Thursday. She scored the attainment of this goal. The third goal was "to remember to ask for medication (on time)". Twice every day, he had to collect his medication at the nurses' station, like all other residents. Both the act of remembering to ask for medication and the punctuality of this act were recorded.

\section{Outcome measures}

The attainment of goals was scored independently by professionals in three work disciplines: the occupational therapist, the nursing staff, and the activity counsellor (carpentry workshop). Attainment of the goals was assessed daily, weekly, or only on specific days, depending on the intended frequency and expected occurrence of the goal tasks.

Goal tasks were scored as "pass" (1 point) or "fail" (no points). These scores were summed and divided by the number of observations, to arrive at an overall mean week score. Final scores for each goal task thus ranged between zero and one, a score closer to one reflecting better performance. An overall mean phase score was also calculated; in each phase the week scores were summed up and divided by the number of observation weeks.
Qualitative information was gathered after the trial by asking the staff to write down how the participant performed during the research period, how the cognitive aid was used, how the participant had experienced the use of the PDA, and what had struck the staff as remarkable during the observations. This written information was compiled by the third author and sent to the first author for analysis.

\section{Results}

\section{Quantitative observations}

Table I presents the mean score for each goal in each trial phase. Figures 1a to $1 \mathrm{c}$ show the results on the three goals. In week 10 of the trial the PDA with PEAT software was not functioning properly due to a technical issue, and therefore the device could not be used in that week.

In the memory watch phase (phase B; weeks 3 and 4) the best scores were attained on all goals. As shown in Figure 1a, the results during the first few weeks of using a PDA were quite variable; the second half of the PDA phase showed higher scores on the first goal, arriving on time (overall score 0.84 ).

On the second goal (Figure 1b), performing a longterm task, measurements in the PDA phase also showed a variable pattern (overall score 0.73 ). The available data seem to suggest an improvement in the attainment of the second goal during the PDA phase. Unfortunately, some measurements, especially in the second half of the PDA phase, were unavailable. This was due to the inadvertent loss of several scoring forms in the clinical setting and to the seemingly inconsistent scoring routine of the staff members who performed the measurements. It appeared that some raters might have recorded the behaviour only when it occurred, and might have forgotten to rate the behaviour when it did not occur.

Measurements regarding the third goal (Figure 1c), remembering to ask for medication, were missing for the second phase, when the memory watch was used. Due to the absence of valid observations during this period and some missing data in the PDA phase, it is difficult to discern a pattern in the outcome. The data 

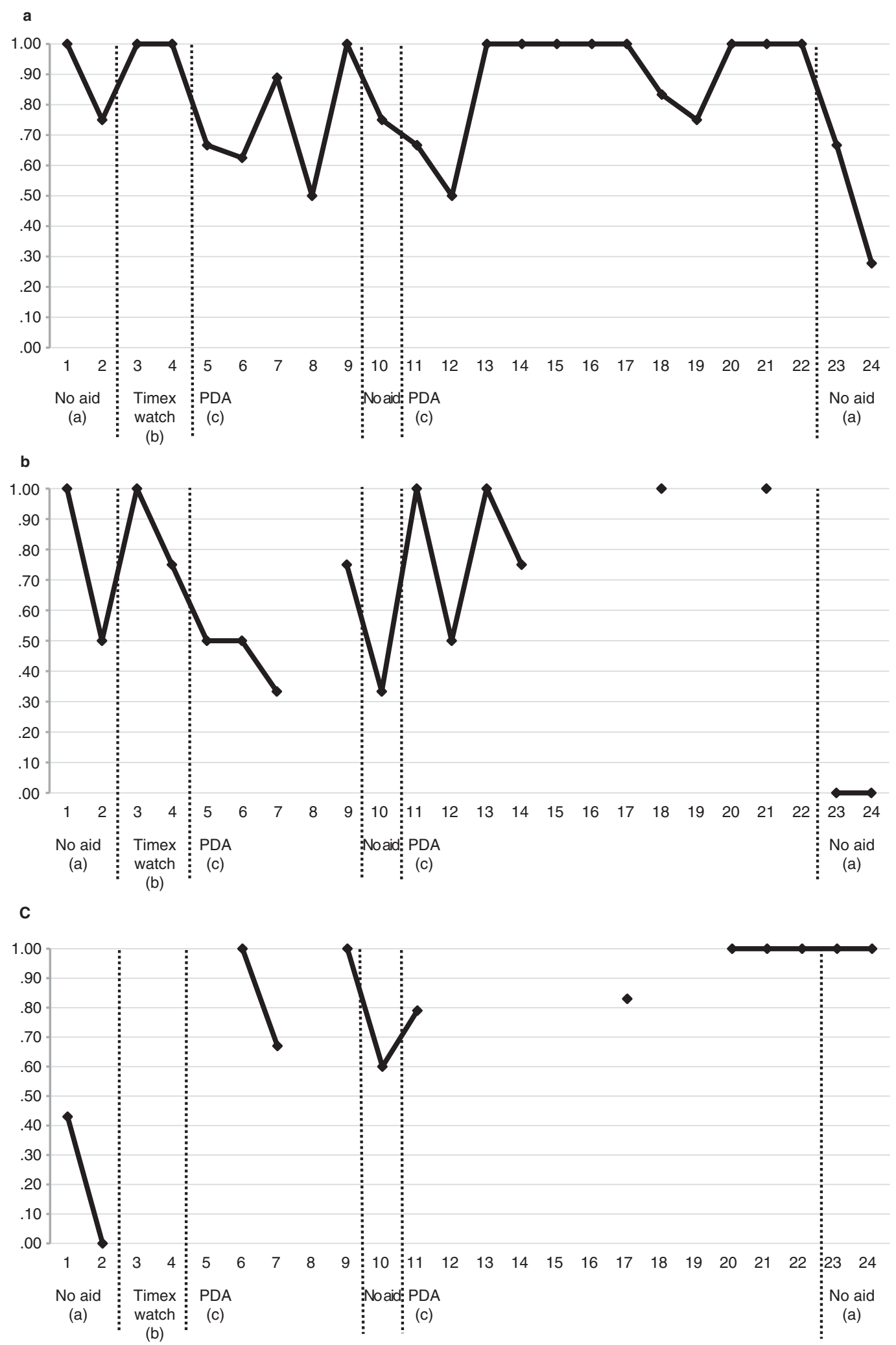

Figure 1. Attainment on goals: mean score for each goal per week: (a) Goal 1: arrive on time - the letters in parentheses refer to the study phase; (b) Goal 2: performing a long-term task - the letters in parentheses refer to the study phase; (c) Goal 3: remember to ask for medication - the letters in parentheses refer to the study phase. 
in Table I suggest a difference between the first phase without an external aid (0.34) and the PDA phase (0.86).

In the last phase without any memory aid, a relapse was observed on goal tasks one (0.47) and two (0.00), but not on behaviour three (1.00).

\section{Qualitative observations by clinical staff}

Clinical observations by the nursing staff showed that near the end of the PDA phase the participant was using the device independently and without cues from the staff. However, a check by the staff remained necessary to prevent mistakes or omissions. The participant took the initiative to use the PDA outside the trained situations, e.g. in order to remember a question that he wanted to ask his therapist, which he wrote down next to his appointment in the PDA. However, not all relevant appointments were entered into the PDA, and in the case of some important appointments (for example with his general practitioner) he needed to be reminded by the staff. His lack of awareness of his amnesia due to Korsakoff syndrome limited optimal use of the PDA, as he did not always realize that he needed external memory support.

The staff also observed that a task not entered into the PDA was more likely to be forgotten by the participant, e.g. his mother's birthday was not entered into the PDA, and when he forgot this event he was very disappointed. In the first week after the PDA phase of the trial it was observed that he was able to attain his goals without the help of an aid, possibly due to the routine he had developed over the preceding weeks, but he had become noticeably more passive. In the second week without an aid he was struggling with being on time and remembering necessary information, e.g. he was unusually late at the activity centre in that week and was more restless, often checking the time and the activity board. If he did remember the appointment he found it difficult to remember the right time, and therefore was present at appointments far too early sometimes. Without the PDA he needed much more structure and help from the nursing staff.

According to the staff, an important advantage of the PDA over the watch was the possibility for the participant to add or change information himself and without delay (in which information can be easily forgotten or lost), which was not feasible with the memory watch.

\section{Experiences of the participant}

In phase four, after he had handed in the PDA again, he reported to his therapist that his debit card had been blocked, because he had used an incorrect ID code (which he had entered as a note on his PDA). He also reported that the PDA was a more efficient aid than the memory watch and, at the end of the trial, he expressed a wish to continue the use of the PDA.

\section{Follow-up}

Nine months after the end of the trial he still used an electronic calendar; however, he did not use the customized software (PEAT) any more. After the trial he purchased his own device, a Smartphone, on which the PEAT software was installed. The combination of this specific device and the PEAT software caused technical difficulties and due to the resulting confusion and frustration the participant became dissatisfied with the device. Together with his family he decided to stop using it, and to continue using the standard calendar software that came with the device instead. However, next to his Smartphone he also used a white board to have an overview of his week's schedule and a paper diary for other appointments. The calendar on his Smartphone is now primarily used to set alarms. He still needs some supervision now and then by his caregivers to keep his calendar up to date and to check whether appointments are correctly entered into the device.

$\mathrm{He}$ no longer is a resident at the clinic but lives in sheltered housing accommodation.

\section{Discussion}

No significant differences were found between the use of the memory watch and the use of the customized PDA installed with the PEAT software. However, the qualitative observations showed that the PDA was perceived as a feasible, more effective, and more comprehensive aid, when compared with the use of a memory watch or using no external aid. Both the staff and the participant himself noted clear advantages over and above the more traditional aids and advocated continued use of the PDA after the trial period.

Furthermore, the participant was able to learn how to use the PEAT software. In the context of earlier research this study shows that a person with Korsakoff syndrome is able to use a slightly more complex electronic aid than only simple pagers or prompting devices. The participant could enter his appointments by himself and could add notes to appointments, if necessary. In earlier studies participants did not perform such complex tasks $(11,12)$. However, it is difficult to compare older studies with the current study, due to the time interval between them, and the widely accepted use of PDAs or smartphones today. Therefore, we hypothesize that persons with Korsakoff syndrome may benefit from using these more 
complex devices because their procedural memory of how to use and interact with a computer device may still be intact. To provide more solid evidence for the effective application of PDAs or smartphones in people with Korsakoff syndrome, this intervention should be tested more systematically and in a large group of participants.

While one recent randomized controlled trial involving persons with acquired brain injury from other causes (e.g. stroke, traumatic brain injury) demonstrated the effectiveness of a PDA with PEAT (6), studies on the application of modern technological cognitive aids in other patient groups with cognitive and intellectual impairments are lacking.

A single case experimental design (SCED) was chosen for this study. SCEDs are very suitable for investigating the efficacy of interventions in participants with specific characteristics. The flexibility and capacity of SCEDs enable the researcher to individually tailor an intervention and its evaluation to the specific characteristics of the individual (15). It also is less time consuming to perform than a controlled trial, which may take months or even years to complete. A compact and flexible research design allows researchers and clinicians to keep up with the pace of technological developments. Although a large number of measurements should ensure sufficient reliability of the results, it does not control for environmental factors as well as a randomized controlled trial (RCT) does. However, this SCED is in fact a spin-off study of a larger RCT study (6), and it was therefore justified to use the current design to explore the use of a PDA with PEAT software in a person with another form of brain injury than in the main study, in this case Korsakoff syndrome.

The current study as a SCED (15) shows some limitations. First, for goals two and three, several weeks of measurements are missing. Nevertheless, a treatment response on the goal tasks was at least suggested by the available data. Second, the interrater reliability could have been reduced by the seemingly inconsistent scoring routine. Some raters might have recorded the behaviour only when it occurred, and might have forgotten to rate the behaviour when it did not occur. Finally, all raters were involved in the treatment of the participant and may therefore be potentially biased in their observations. The qualitative data were obtained from the staff. In hindsight it was considered an omission not to obtain formal feedback from the patient himself.

The participant in this study was typical of people with Korsakoff syndrome: he was male, in his forties and had a history of alcohol abuse. Furthermore, as in more than half of all people with Korsakoff, he suffered from Wernicke's encephalopathy (21). He had a typical neuropsychological profile, including severe memory impairment, confabulation, and a lack of initiative. Therefore it seems reasonable to propose that other persons with Korsakoff syndrome may also benefit from similar electronic cognitive aids. Nonetheless, the personal preferences of the potential user are important in the actual choice of either electronic or paper-and-pencil aids. Furthermore, the participant in this study received a great deal of support from his therapist and family. However, due to his lack of insight into his cognitive deficits and cognitive support needs, supervision by his caregivers was required to make sure he continued to use his calendar appropriately.

A distinct difference from people with other causes of brain injury is a history of alcohol abuse, which could have an adverse effect on the availability of a support system (7), and therefore affect the adherence to treatment (22). Also, the risk of relapse into alcohol abuse and the fact that these persons have a higher likelihood of developing psychiatric disorders (10) could diminish the adherence to treatment and therefore the applicability of digital cognitive aids.

In conclusion, the current study shows that it was possible to train a person with Korsakoff syndrome to use a customized PDA as a cognitive aid. Furthermore, both the participant and clinical staff members favoured the customized PDA over the memory watch as a cognitive aid. The application of handheld electronic devices installed with dedicated software in a rehabilitation setting is not more time consuming than ordinary aids, although the costs are higher. This could be a significant obstacle for a large number of potential users. A scaled-up effectiveness study in this patient group is necessary to provide more solid evidence to justify the routine clinical use of PDAs as memory supports for people with Korsakoff syndrome.

\section{Acknowledgements}

This project was supported by a grant from the Netherlands Organization for Health Research and Development (ZonMW) The Hague, The Netherlands.

Declaration of interest: The authors report no conflicts of interest. The authors alone are responsible for the content and writing of the paper.

\section{References}

1. Stapleton S, Adams M, Atterton L. A mobile phone as a memory aid for individuals with traumatic brain injury: A preliminary investigation. Brain Inj 2007;21:401-11. 
2. Wilson BA, Emslie H, Quirk K, Evans J, Watson P. A randomized control trial to evaluate a paging system for people with traumatic brain injury. Brain Inj 2005; 19: 891-4.

3. Gentry T. PDAs as cognitive aids for people with multiple sclerosis. Am J Occup Ther 2008;62:18-27.

4. Depompei R, Gillette Y, Goetz E, Xenopoulos-Oddsson A, Bryen D, Dowds M. Practical applications for use of PDAs and smartphones with children and adolescents who have traumatic brain injury. NeuroRehabilitation 2008;23: 487-99.

5. De Joode E, van Heugten C, Verhey F, van Boxtel M. Efficacy and usability of assistive technology for patients with cognitive deficits: A systematic review. Clin Rehabil 2010;24:701-14.

6. De Joode EA, van Heugten CM, Verhey FRJ, van Boxtel MPJ. Effectiveness of an electronic cognitive aid in patients with acquired brain injury: A multicentre randomised parallelgroup study. Neuropsychol Rehabil 2013;23:133-56.

7. Arts NJM. Het syndroom van Korsakov (I): ontstaan en geheugenstoornissen [Korsakoff syndrome (I): Origination and memory disorders]. Neuropsychiatrie \& Gedragsneurologie 2004;8:2-9.

8. Kopelman MD. The Korsakoff syndrome. Br J Psychiatry 1995;166:154-73.

9. Arts NJM. Het syndroom van Korsakov (II): centraal executieve stoornissen en behandeling [Korsakoff syndrome (II): Central executive disorders and treatment]. Neuropsychiatrie \& Gedragsneurologie 2004;10:10-16.

10. Kopelman MD, Thomson AD, Guerrini I, Marshall EJ. The Korsakoff syndrome: Clinical aspects, psychology and treatment. Alcohol Alcohol 2009;44:148-54.

11. Wilson BA, Baddeley B, Evans J, Shiel A. Errorless learning in the rehabilitation of memory impaired people. Neuropsychol Rehabil 1994;4:307-26.
12. Morgan J, McSharry K, Sireling L. Comparison of a system of staff prompting with a programmable electronic diary in a patient with Korsakoff's syndrome. Intl J Social Psychiatry 1990;36:225-9.

13. O'Connell ME, Mateer CA, Kerns KA. Prosthetic systems for addressing problems with initiation: Guidelines for selection, training, and measuring efficacy. NeuroRehabilitation 2003; 18:9-20.

14. Smith I, Hillman A. Management of alcohol Korsakoff syndrome. Adv Psychiatr Treat 1999;5:271-8.

15. Beck AT, Steer RA, Brown GK. Manual for the Beck Depression Inventory-II. San Antonio, TX: Psychological Corporation; 1996.

16. Tate RL, McDonald S, Perdices M, Togher L, Schultz R, Savage $S$. Rating the methodological quality of single-subject designs and n-of-1 trials: introducing the Single-Case Experimental Design (SCED) Scale. Neuropsychol Rehabil 2008; 18:385-401.

17. Timex. 2011. [cited 2011 November 16th] available from http://www.timex.com.

18. Abilia. Handifon. Abilia. org. 2011. [cited 2011] available from http://www.abilia.org.uk/produkter/index.aspx?intshopcmd= \&group=1306\&prod=261138.

19. Gorman P, Dayle R, Hood CA, Rumrell L. Effectiveness of the ISAAC cognitive prosthetic system for improving rehabilitation outcomes with neurofunctional impairment. NeuroRehabilitation 2003;18:57-67.

20. Levinson R. The Planning and Execution Assistant and Trainer (PEAT). J Head Trauma Rehabil 1997;12:85-91.

21. Victor M, Adams RD, Collins GH. The Wernicke-Korsakoff syndrome and related neurologic disorders due to alcoholism and malnutrition. 2nd ed. Philadelphia: Davis; 1989.

22. DiMatteo M. R. Social support and patient adherence to medical treatment: A meta-analysis. Health Psychol 2004; 23:207-18. 